\title{
Decision-making after ultrasound diagnosis of fetal abnormality
}

\author{
Hilmar H. Bijma • Agnes van der Heide • \\ Hajo I. J. Wildschut
}

Received: 21 July 2007 / Accepted: 23 July 2007 / Published online: 11 October 2007

(C) European Board and College of Obstetrics and Gynaecology 2007

\begin{abstract}
During the last few decades, the use of ultrasonography for the detection of fetal abnormalities has become widespread in many industrialised countries. This resulted in a shift in timing of the diagnosis of congenital abnormalities in infants from the neonatal period to the prenatal period. This has major implications for both clinicians and the couples involved. In case of ultrasound diagnosis of fetal anomaly, there are several options for the obstetric management, ranging from standard care to nonaggressive care and termination of pregnancy. This essay explores the context of both clinical and parental decision making after ultrasound diagnosis of fetal abnormality, with emphasis on the Dutch situation. While normal findings at ultrasound examination have strong beneficial psychological effects on the pregnant woman and her partner, the couple is often ill prepared for bad news about the health of their unborn child in the case of abnormal findings. This is, in particular, true in settings where ultrasonography for the detection of fetal abnormalities is offered as an integral part of antenatal care without appropriate counselling. An important question is to what extent the couple should be supported in decision making when a fetal abnormality is diagnosed. In this context, the parental perception of having a choice varies markedly. When parents consider end-of-life decisions, they experience both ambivalent and emotional feelings. On the one hand, they are committed to their
\end{abstract}

H. H. Bijma • H. I. J. Wildschut ( $\)$

Department of Obstetrics and Gynecology,

Erasmus University Medical Center,

P.O. box 2040, 3000CA Rotterdam, The Netherlands

e-mail: h.wildschut@erasmusmc.nl

A. van der Heide

Department of Public Health, Erasmus University Medical Center,

Rotterdam, The Netherlands pregnancy, while on the other hand, they want to protect their child, themselves and the family from the burden of severe disability. These complex parental reactions have implications for the counselling strategy.

Keywords Fetal abnormality · Prenatal detection rate .

Ultrasound · Parental decision-making · End-of-life decisions

\section{Congenital abnormalities}

Congenital abnormalities are the main cause of infant death in industrialised countries $[1,2]$. Congenital abnormalities are frequently diagnosed before birth, as many of the major fetal abnormalities can be detected by a prenatal ultrasound examination [3-5]. From data derived from a routine ultrasound screening setting of an unselected population in Oxford [6], the estimated birth prevalence of infants with abnormalities is $2.2 \%$ (Fig. 1). Just more than half (55\%) of them were diagnosed with abnormalities that were identified prenatally. Currently, ultrasound scanning is considered the most important tool for prenatal diagnosis of fetal congenital abnormalities. It detects the majority but certainly not all of the fetal abnormalities [6]. In specialist centres for prenatal diagnosis, detection rates of fetal abnormalities range from 80 to $95 \%$ [4, 7]. Detection rates in screening settings are probably lower. The detection rates also depend on the nature, type and numbers of abnormalities. For example, prenatal detection rates of neural tube defects approximate $98 \%$ while those of congenital heart defects are about $38 \%$. Apart from the nature of the fetal abnormality, maternal obesity has a considerable impact on detection rates [8].

The study in Oxford also addressed the overall impact of prenatal ultrasound diagnosis in terms of numbers of infants 


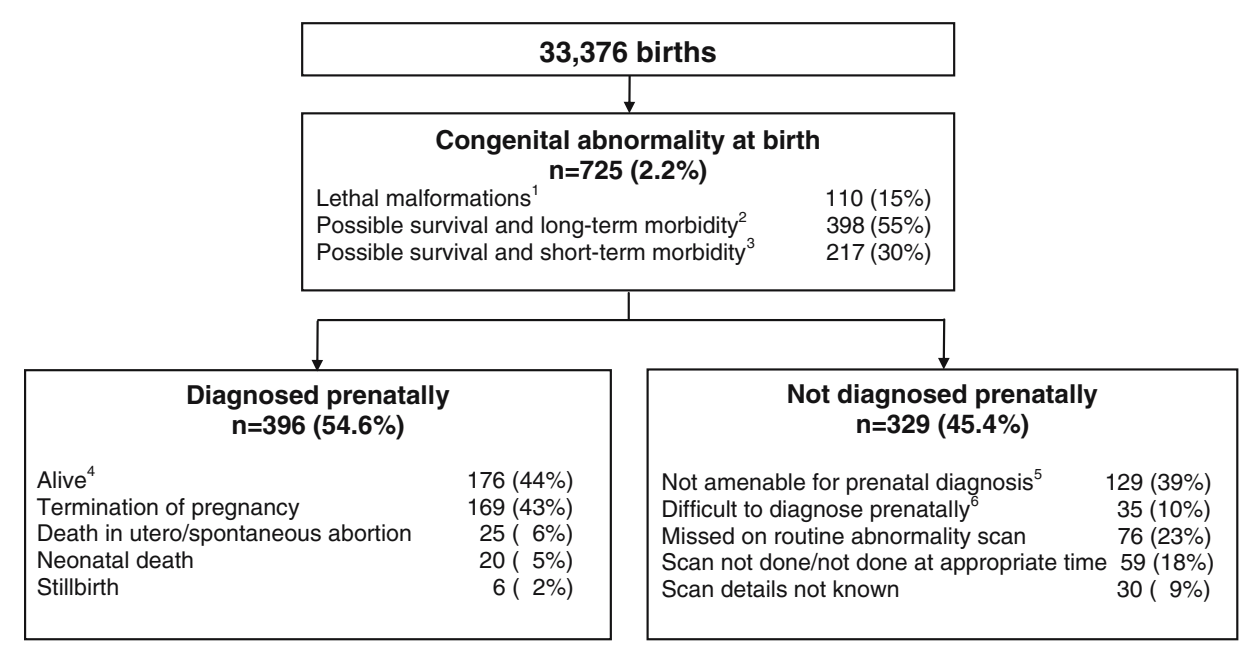

Fig. 1 Overview of prenatal detection of congenital abnormality when prenatal screening is offered routinely in an unselected population in Oxford, 1991_1995; births included all births over 20 weeks and all pregnancies terminated because of fetal abnormality detected at any age of gestation. 1, e.g. anencephaly, trisomy 13, trisomy 18, hypoplastic left heart, renal agenesis, Meckel Gruber syndrome; 2, e.g. spina bifida, hydrocephalus, Down's syndrome,

complex cardiac malformations, diaphragmatic hernia, abdominal wall defects; 3, e.g. non-complex cardia malformations, facial clefts, club foot, hypospadia; 4, two infants died after the neonatal period; 5, e.g. skin abnormalities, hypospadia, congenital dislocation of the hip, cleft palate, atrial-septal defect; 6 , e.g. tracheo-oesofageal fistula or fistula, coarctation of aorta, polydactyly, ambiguous genitalia

born with conditions that result in mortality or severe morbidity (Fig. 1) [6]. In fact, when severe congenital abnormalities are detected prenatally, termination of pregnancy is an option for the couple involved. In the majority of end-of-life decisions in the prenatal period, suspicion of fetal abnormality was first aroused after ultrasound scan [6]. Hence, the practice of ultrasound scanning is closely related to that of end-of-life decisions.

\section{Developments in fetal ultrasound}

Since the early sixties, when the first ultrasound images of the fetus were made, ultrasound has evolved into the most important diagnostic tool in fetal medicine [9]. First, only static images of the fetus were available. In 1977, real-time scanning was introduced, which allowed for moving images of the fetus. Soon thereafter, ultrasound became widely available in clinical practice. In a short period of time, a myriad of reports on both normal and abnormal anatomy of the fetus appeared in the medical literature. Nowadays, routine ultrasound examination during pregnancy is an integral part of antenatal care in most industrialised countries [9-11]. Routine ultrasound examination typically includes a dating scan in the first trimester of pregnancy and a fetal abnormality scan at approximately 18-20 weeks' gestation [9].

In countries with a routine ultrasound screening policy, more than half of all congenital abnormalities are diagnosed prenatally, including $74 \%$ of the major abnormalities (i.e. abnormalities that have implications for the infant's health)

and $46 \%$ of the minor abnormalities (i.e. abnormalities that have no implications for the infant's health) $[6,12]$.

\section{Ultrasound screening}

From the perspective of public health, the potential benefits and limitations of ultrasound screening for fetal abnormalities have been debated extensively $[4,9]$. To date, reports on the benefits of ultrasound screening for the detection of both lethal and non-lethal abnormalities among unselected populations are inconclusive [13]. Randomised controlled trials have been done but have used perinatal mortality and morbidity as outcome variables. Moreover, in research settings, there was a wide variation in expertise levels of sonographers. The interpretation of the research findings is further impeded by the time period of the studies being conducted; ultrasound nowadays is more advanced than in former days [10]. These methodological problems are reflected in an enormous variation of reported overall sensitivity of the detection of congenital abnormalities, which ranges between 14 and 96\% [3-5, 13]. Apart from these methodological flaws, the use of perinatal mortality and morbidity as the most important outcome variables is questionable [10]. Other outcome variables, such as improved information of pregnant women about the health status of their offspring, enhanced care for the affected neonate, better fetal-maternal bonding, the potential prevention of a 'wrongful life' are relevant as well [13]. These issues warrant additional questions about the aim of screening. The answer to these questions should not only 
pertain to medical data but should also incorporate moral choices $[10,11,14]$.

In The Netherlands, the implementation of ultrasound screening into clinical practice has been a matter of strong debate [11]. Initially, the government decided that ultrasound is only to be offered for 'genetic' indications, i.e. targeted at women at increased risk of congenital abnormalities in offspring [11]. This policy should be seen within the Dutch sociocultural context. Dutch law typically bans population screening, unless certain conditions are fulfilled, such as the availability of effective treatment for the outcome of interest [11]. In the context of prenatal screening for fetal abnormalities, abortion is not considered as an "effective" modality. Furthermore, there were concerns about the implications of prenatal screening in terms of medicalisation of the pregnancy and regarding the position of handicapped people in the society at large [11]. Only recently, Dutch law became more compliant, which resulted in a trend towards offering all pregnant women an ultrasound examination at 20 weeks' gestation.

The government's initial decision not to incorporate routine ultrasound screening into clinical practice resulted in large practice variations, i.e., some women having no ultrasound examination at all, while others having a two-scan policy or a 'pleasure scan' in a commercial setting. The latter may give false reassurance as these ultrasound examinations are not intended for the detection of fetal abnormalities $[11,15]$. Until recently, there were neither formal guidelines for the timing of the ultrasound and counselling nor for qualifications of sonographers. So even if women have had one or multiple ultrasound examinations, potentially detectable major fetal abnormalities were still missed.

\section{Psychological effects of normal ultrasound}

Normal findings at ultrasound examination have strong beneficial psychological effects on the pregnant woman and her partner. For couples, ultrasound is a way of 'meeting' the unborn child ${ }^{1}$ [16-19]. The personalisation of the fetus enhances both maternal-fetal bonding and bonding of the pregnant woman and her partner [18, 20, 21]. A normal ultrasound reassures parents about their pregnancies [20, 22-25]. The positive effects of ultrasound are stronger when more feedback is provided, such as showing images on an additional monitor and explaining what can be seen [20,24].

\footnotetext{
${ }^{1}$ A couple's reaction to a normal ultrasound: 'The baby becomes more real... once you see the scan, that all changes. It's no longer your imagination at work, but you have this real image of a baby. You can see so much detail... it is amazing, his little fingers and toes, his eyes, oh, everything. It is magical, so awe inspiring to see' Puddifoot JE, Johnson MP. The legitimacy of grieving: the partner's experience at miscarriage. Soc Sci Med 1997;45:837-45.
}

In fact, fetal ultrasound is highly appreciated by pregnant women and their partners [19, 25-27]. Most women consider ultrasound examinations as an integral part of antenatal care [26]. However, frequently, women lack information about the purpose of ultrasound examinations and its technical limitations. As a result, women are often unprepared for adverse findings [27, 28].

\section{Psychological effects of abnormal ultrasound}

The news of abnormal findings of the ultrasound examination frequently comes unexpectedly and is often intensely shocking for the would-be parents, in particular, when major congenital abnormalities are encountered [27, 29]. Pregnant women and their partners may have several emotional reactions when fetal abnormalities are revealed. Firstly, they may have negative feelings typically associated with psychological traumas in general, such as anxiety, grief, anger, loneliness, hopelessness, prostration and guilt [28-30, 32, 33]. These feelings may be aggravated by the loss of the imagined future, as the pregnancy may end in the daily reality of having no child or a severely handicapped child, requiring readjustments of the entire family. These negative feelings can be enhanced by the confrontation with reality, when having to decide about very pragmatic issues 'should I furnish the nursery?', 'should I make arrangements for the funeral?', and 'what should I tell my other child?'. Finally, some parents experience a loss of reference. The news of a fetal abnormality in an apparently uneventful pregnancy usually comes so unexpectedly, and is in such contrast with the pleasant experiences that often goes along with pregnancy, that parents have severe difficulty with grasping the facts. It seems so unreal that the child, who is kicking inside the womb, is severely disabled and will perhaps die, thereby making life meaningless. When parents consider pregnancy termination, the ambivalent feelings they experience may enhance this loss of reference. On the one hand, they are committed to their-desired and intended - pregnancy while on the other hand they want to protect their child, themselves and the family from the burden of severe disability [34].

\section{End-of-life decisions after ultrasound diagnosis of fetal abnormality}

With the burgeoning of ultrasound, questions around the appropriate obstetric management in case of sonographically established fetal abnormalities have arisen. Should we apply all means to keep alive a fetus with a very poor prognosis? Do medical professionals in the field of perinatal medicine agree on fetal prognosis after ultrasound 


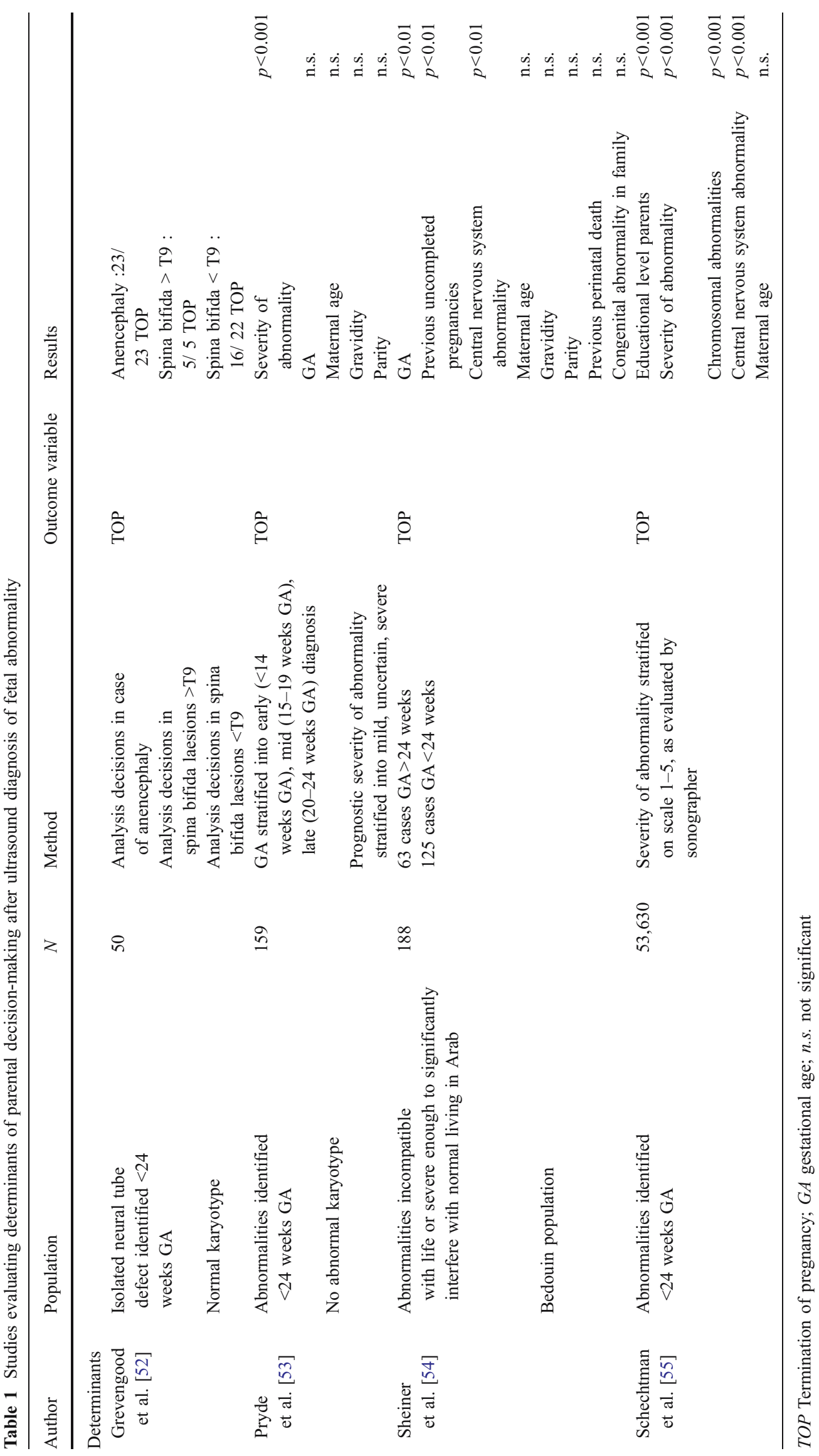


diagnosis of fetal abnormality? How should obstetric and neonatal management be attuned? How do parents view end-of-life decisions concerning their unborn infant? These and other issues have opened a new field of research: endof-life decision-making after ultrasound diagnosis of fetal abnormality. End-of-life decisions are decisions about medical interventions at the end of life, which certainly or probably hasten death [35].

Two kinds of end-of-life decisions can be distinguished after ultrasound diagnosis of fetal abnormality. That is, (1) non-aggressive obstetric management and (2) termination of pregnancy. A non-aggressive obstetric management refers to an obstetric management in which interventions needed to sustain fetal life are forgone because of the poor prognosis of the fetus concerned. Chervenak and McCullough [36] first reported the non-aggressive obstetric management approach in 1989. They described 13 cases where such approach was adopted. They regarded a non-aggressive obstetric management as permissible, and even preferable, when there is certainty of death or absence of cognitive developmental capacity as outcome of the congenital abnormality. They argued that, in such cases, the fetus does not benefit from obstetric intervention, while such intervention may harm the pregnant woman and interfere with her autonomy [36, 37]. However, empirical data needed for a balanced professional and societal debate about forgoing fetal lifesustaining treatment are scarce [36, 38, 39].

Termination of pregnancy is a management option, in which the pregnancy is terminated with the explicit intention of hastening fetal death. Termination of pregnancy is done by induction of labour, which may be preceded by fetal intracardial potassium injection. The first termination of pregnancy after ultrasound diagnosis of fetal abnormality was reported in 1972 by Campbell et al. [40]. Their report concerned a fetus with anencephaly. Termination of pregnancy has far-reaching implications for the couple. It bears life-long lasting consequences and evokes strong emotions of the couples involved [41, 42].

End-of-life decision makings after ultrasound diagnosis of fetal abnormality have to take into account both the interest of the fetus and the pregnant woman. Therefore, these difficult decisions are usually made by multidisciplinary teams [43-47]. These typically consist of obstetricians, neonatologists, paediatric surgeons and other paediatric specialists, such as paediatric urologists, paediatric neurologists and paediatric neurosurgeons [43-47]. However, little is known about how exactly decisions are being taken in these teams.

Parental decision making after ultrasound diagnosis of fetal abnormality remains a largely unknown territory. Table 1 shows the studies to date, which evaluate determinants of parental decision regarding termination of pregnancy. Low gestational age, severe abnormality, involvement of the central nervous system, previous uncompleted pregnancies, low maternal educational level and the presence of chromosomal abnormalities are associated with high rates of women deciding for termination of pregnancy. However, these data are not conclusive and do not reflect why and in what way some factors are important for the parents. Sandelowski and Jones [48] studied parental decision making concerning prenatal diagnosis of fetal abnormality in more depth. She interviewed 15 women and 12 of their partners. Her study showed that women have highly variable perceptions of choice. In fact, women in comparable circumstances feel differently about whether or not they have a choice about the future of their pregnancy [48].

\section{Legal context and current guidelines}

In The Netherlands, law prohibits termination of pregnancy at a gestational age of 24 weeks or beyond. However, in case of good clinical practice, physicians will not be prosecuted by the public prosecutor [49-51]. Good clinical practice is described in guidelines that were made by a collaborative group of the Ministry of Health, Ministry of Justice and the Dutch Society of Obstetricians and Gynaecologists. According to these guidelines, when parents persist in their request for termination of pregnancy, this will be granted when fetal prognosis is considered lethal. Fetal prognosis is considered lethal if (1) the infant has no chance of survival and the abnormalities cannot be treated or (2) the infant has a chance of extra-uterine survival but post-natal use of life-prolonging medical treatment is considered futile [50].

\section{In conclusion}

In most industrialised countries ultrasonography for the detection of fetal structural abnormalities has become an integral part of antenatal care. In general, women are often ill prepared for bad news about the health of their unborn child. Upon the detection of severe fetal abnormalities, they could be faced with decisions whether or not to continue pregnancy. This essay explores the context of decision making after ultrasound diagnosis of fetal abnormality, with emphasis on the Dutch situation. In the case of fetal abnormalities, perception of choice among pregnant women varies markedly, challenging the counselling strategy.

\section{References}

1. Petrini J, Damus K, Russell R, Poschman K, Davidoff MJ, Mattison D (2002) Contribution of birth defects to infant mortality in the United States. Teratology 66 Suppl 1:S3-S6 
2. Lee K, Khoshnood B, Chen L, Wall SN, Cromie WJ, Mittendorf RL (2001) Infant mortality from congenital malformations in the United States, 1970-1997. Obstet Gynecol 98:620-627

3. Lys F, De Wals P, Borlee-Grimee I, Billiet A, Vincotte-Mols M, Levi S (1989) Evaluation of routine ultrasound examination for the prenatal diagnosis of malformation. Eur J Obstet Gynecol Reprod Biol 30:101-109

4. Levi S (2002) Ultrasound in prenatal diagnosis: polemics around routine ultrasound screening for second trimester fetal malformations. Prenat Diagn 22:285-295

5. Carrera JM, Torrents M, Mortera C, Cusi V, Munoz A (1995) Routine prenatal ultrasound screening for fetal abnormalities: 22 years' experience. Ultrasound Obstet Gynecol 5:174-179

6. Boyd PA, Chamberlain P, Hicks NR (1998) 6-year experience of prenatal diagnosis in an unselected population in Oxford, UK. Lancet 352:1577-1581

7. Wladimiroff JW, Cohen-Overbeek TE, Ursem NT, Bijma H, Los FJ (2003) Geavanceerd ultrageluidonderzoek naar aangeboren afwijkingen in Rotterdam; 20 jaar ervaring [Twenty years of experience in advanced ultrasound scanning for fetal abnormalities in Rotterdam]. Ned Tijdschr Geneeskd 147:2106-2110

8. Tabor A, Zdravkovic M, Perslev A, Moller LK, Pedersen BL (2003) Screening for congenital malformations by ultrasonography in the general population of pregnant women: factors affecting the efficacy. Acta Obstet Gynecol Scand 82:1092-1098

9. McNay MB, Fleming JE (1999) Forty years of obstetric ultrasound 1957-1997: from A-scope to three dimensions. Ultrasound Med Biol 25:3-56

10. Romano PS, Waitzman NJ (1998) Can decision analysis help us decide whether ultrasound screening for fetal abnormalities is worth it? Ann N Y Acad Sci 847:154-172

11. Health Council of the Netherlands. Prenatal Screening: Down's syndrome, neural tube defects, routine-ultrasonography (2001) The Hague: Health Council of the Netherlands, publication no. 2001/11

12. Grandjean H, Larroque D, Levi S (1998) Sensitivity of routine ultrasound screening of pregnancies in the Eurofetus database. The Eurofetus Team. Ann N Y Acad Sci 847:118-124

13. Wladimiroff JW (2006) Routine ultrasonography for the detection of fetal structural anomalies. In: Wildschut HIJ, Weiner CP and Peters TJ (eds) When to screen in obstetrics and gynecology, 2nd edn. WB Saunders, Philadelphia, pp 244-252

14. Getz L, Kirkengen AL (2003) Ultrasound screening in pregnancy: advancing technology, soft markers for fetal chromosomal aberrations, and unacknowledged ethical dilemmas. Soc Sci Med $56: 2045-2057$

15. Wildschut HI, ten Hoope-Bender P, Borkent-Polet M, Traas H, van Agt HM, de Kroon ML et al (1999). Practice variation of test procedures reportedly used in routine antenatal care in The Netherlands. Acta Obstet Gynecol Scand 78:27-32

16. Puddifoot JE, Johnson MP (1997) The legitimacy of grieving: the partner's experience at miscarriage. Soc Sci Med 45:837-845

17. Kowalcek I, Huber G, Bieniakiewitz I, Lammers C, Brunk I, Gembruch U (2003) The influence of gestational age on depressive reactions, stress and anxiety of pregnant women and their partners in relation to prenatal diagnosis. J Psychosom Obstet Gynaecol 24:239-245

18. Bricker L, Garcia J, Henderson J, Mugford M, Neilson J, Roberts T et al (2000) Ultrasound screening in pregnancy: a systematic review of the clinical effectiveness, cost-effectiveness and women's views. Health Technol Assess 4:i-vi, 1-193

19. Harris G, Connor L, Bisits A, Higginbotham N (2004) "Seeing the baby": pleasures and dilemmas of ultrasound technologies for primiparous Australian women. Med Anthropol Q 18:23-47

20. Reading AE, Cox DN (1982) The effects of ultrasound examination on maternal anxiety levels. J Behav Med 5:237-247
21. Sklansky M, Tang A, Levy D, Grossfeld P, Kashani I, Shaughnessy $\mathrm{R}$ et al (2002) Maternal psychological impact of fetal echocardiography. J Am Soc Echocardiogr 15:159-166

22. Harris CE (1991) Aborting abnormal fetuses: the parental perspective. J Appl Philos 8:57-68

23. Bjorkhem G, Jorgensen C, Hanseus K (1997) Parental reactions to fetal echocardiography. J Matern Fetal Med 6:87-92

24. Zlotogorski Z, Tadmor O, Duniec E, Rabinowitz R, Diamant Y (1996) The effect of the amount of feedback on anxiety levels during ultrasound scanning. J Clin Ultrasound 24:21-24

25. Larsen T, Nguyen TH, Munk M, Svendsen L, Teisner L (2002) Ultrasound screening in the 2nd trimester. The pregnant woman's background knowledge, expectations, experiences and acceptances. Ultrasound Obstet Gynecol 15:383-86

26. Georges E (1996) Fetal ultrasound imaging and the production of authoritative knowledge in Greece. Med Anthropol Q 10:157-175

27. Garcia J, Bricker L, Henderson J, Martin MA, Mugford M, Nielson J et al (2002) Women's views of pregnancy ultrasound: a systematic review. Birth 29:225-250

28. Statham H, Solomou W, Chitty L (2000) Prenatal diagnosis of fetal abnormality: psychological effects on women in low-risk pregnancies. Bailliere's Best Pract Res Clin Obstet Gynaecol 14:731-747

29. Detraux JJ, Gillot-de Vries F, Vanden Eynde S, Courtois A, Desmet A (1998) Psychological impact of the announcement of a fetal abnormality on pregnant women and on professionals. Ann N Y Acad Sci 847:210-219

30. Hunfeld JA, Wladimiroff JW, Passchier J, Venema-Van Uden MU, Frets PG, Verhage F (1993) Emotional reactions in women in late pregnancy (24 weeks or longer) following the ultrasound diagnosis of a severe or lethal fetal malformation. Prenat Diagn 13:603-612

31. Langer M, Ringler M (1989) Prospective counselling after prenatal diagnosis of fetal malformations: interventions and parental reactions. Acta Obstet Gynecol Scand 68:323-329

32. Leuthner SR, Bolger M, Frommelt M, Nelson R (2003) The impact of abnormal fetal echocardiography on expectant parents' experience of pregnancy: a pilot study. J Psychosom Obstet Gynaecol 24:121-129

33. Mitchell LM (2004) Women's experiences of unexpected ultrasound findings. J Midwifery Womens Health 49:228-234

34. Britt DW, Risinger ST, Mans MK, Evans MI (2002) Devastation and relief: conflicting meanings of detected fetal abnormalities. Ultrasound Obstet Gynecol 20:1-5

35. Groenewoud JH (2002) End-of-life-decisions in medicine, empirical studies on practices and attitudes in the Netherlands. Erasmus University Medical Center Rotterdam

36. Chervenak FA, McCullough LB (1989) Nonaggressive obstetric management. An option for some fetal abnormalities during the third trimester. JAMA 261:3439-3440

37. Chervenak FA, McCullough LB, Skupski D, Chasen ST (2003) Ethical issues in the management of pregnancies complicated by fetal abnormalities. Obstet Gynecol Surv 58:473-483

38. Kirkinen P, Jouppila P, Herva R (1992) Fatal fetal abnormalities. Route of delivery and effect of the development of antepartum diagnostics in the last 13 years. J Reprod Med 37:645-648

39. Spinnato JA, Cook VD, Cook CR, Voss DH (1995) Aggressive intrapartum management of lethal fetal abnormalities: beyond fetal beneficence. Obstet Gynecol 85:89-92

40. Campbell S, Johnstone FD, Holt EM, May P (1972) Anencephaly: early ultrasonic diagnosis and active management. Lancet 2 : $1226-1227$

41. White-Van Mourik MC, Connor JM, Ferguson-Smith MA (1992) The psychosocial sequelae of a second trimester termination of pregnancy for fetal abnormality over a two year period. Birth Defects Orig Artic Ser 28:61-74 
42. White-Van Mourik MC, Connor JM, Ferguson-Smith MA (1990) Patient care before and after termination of pregnancy for neural tube defects. Prenat Diagn 10:497-505

43. Crombleholme TM, D'Alton M, Cendron M, Alman B, Goldberg MD, Klauber GT et al (1996) Prenatal diagnosis and the pediatric surgeon: the impact of prenatal consultation on perinatal management. J Pediatr Surg 31:156-162

44. Luks FI, Carr SR, Feit LR, Rubin LP (2003) Experience with a multidisciplinary antenatal diagnosis and management model in fetal medicine. J Matern Fetal Neonatal Med 14:333-337

45. Aite L, Trucchi A, Nahom A, Spina V, Bilancioni E, Bagolan P (2002) Multidisciplinary management of fetal surgical abnormalities: the impact on maternal anxiety. Eur J Pediatr Surg 12: 90-94

46. Kemp J, Davenport M, Pernet A (1998) Antenatally diagnosed surgical abnormalities: the psychological effect of parental antenatal counseling. J Pediatr Surg 33:1376-1379

47. Scher MS, Kidder BM, Shah D, Bangert BA, Judge NE (2004) Pediatric neurology participation in a fetal diagnostic service. Pediatr Neurol 30:338-344

48. Sandelowski M, Jones LC (1996) Healing fictions': stories of choosing in the aftermath of the detection of fetal abnormalities. Soc Sci Med 42:353-361

49. Bosma JM, van der Wal G, Hosman-Benjaminse SL (1996) Late zwangerschapsafbreking in Noord-Holland. II Zorgvuldigheid vooraf en toetsing achteraf [Late pregnancy interruption in
Noord-Holland. II. Carefulness before and review afterwards]. Ned Tijdschr Geneeskd 140:605-609

50. Ministry H (1998) Late termination of pregnancy: care and assessment [Late zwangerschapsafbreking: zorgvuldigheid en toetsing]. Ministry of Health, Ministry of Justice, Rijswijk,The Netherlands

51. NVOG (2003) Model Reglement Medisch Handelen Late Zwangerschapsafbreking bij niet met het leven verenigbare afwijkingen vallend onder categorie 1; versie dd 221003

52. Grevengood C, Shulman LP, Dungan JS, Martens P, Phillips OP, Emerson DS et al (1994) Severity of abnormality influences decision to terminate pregnancies affected with fetal neural tube defects. Fetal Diagn Ther 9:273-277

53. Pryde PG, Isada NB, Hallak M, Johnson MP, Odgers AE, Evans MI (1992) Determinants of parental decision to abort or continue after non-aneuploid ultrasound-detected fetal abnormalities. Obstet Gynecol 80:52-56

54. Sheiner E, Shoham-Vardi I, Weitzman D, Gohar J, Carmi R (1998) Decisions regarding pregnancy termination among Bedouin couples referred to third level ultrasound clinic. Eur J Obstet Gynecol Reprod Biol 76:141-146

55. Schechtman KB, Gray DL, Baty JD, Rothman SM (2002) Decision-making for termination of pregnancies with fetal abnormalities: analysis of 53,000 pregnancies. Obstet Gynecol 99:216-222 